\title{
Antenatally Diagnosed Suprarenal Mature Cystic Teratoma with Down Syndrome
}

\author{
Aditya Pratap Singh ${ }^{1}$, Ramesh Tanger ${ }^{1}$, Maryem Ansari ${ }^{2}$ Arun Kumar Gupta ${ }^{1}$ Dinesh Kumar Barolia ${ }^{1}$
}

1 Department of Pediatric Surgery, SMS Medical College Jaipur, Rajasthan, India

2. Department of Pathology, SMS Medical College Jaipur, Rajasthan, India

\section{ABSTRACT}

Background: Teratoma is a germ cell tumor (GCT) arising from totipotent stem cells that differentiate into the tissues that are foreign to the anatomic site. Teratoma at the suprarenal location is extremely rare. The association with the Down syndrome also makes it unusual.

Case Report: We are presenting here a case of one-year-old female infant with Down syndrome who had an antenatal diagnosis of right suprarenal mass. Laparotomy revealed a large cystic mass in the right suprarenal location which was completely excised. Right adrenal gland could not be seen separately from the mass. The histological diagnosis was a mature cystic teratoma.

Conclusion: Adrenal teratoma is rare and may be considered in the differential diagnosis of antenatally diagnosed suprarenal lesion. Its association with Down syndrome is rare finding.

Key words: Mature cystic teratoma; Antenatal diagnosis; Suprarenal teratoma; Down syndrome

Correspondence*: Correspondence: Aditya Pratap Singh, Department of Pediatric Surgery, SMS Medical College Jaipur, Rajasthan, India.

E-mail: dr.adisms@gmail.com

(C) 2018, Singh et al. .

Submitted: 15-04-2018

Accepted: 05-06-2018

Conflict of Interest: None

Source of Support: Nil

This is an open-access article distributed under the terms of the Creative Commons Attribution License, which permits unrestricted use, distribution, and reproduction in any medium, provided the original work is properly cited.

\section{INTRODUCTION}

Suprarenal tumors, diagnosed antenatally or in the early neonatal period, are always a diagnostic dilemma. Teratomas in the retroperitoneum are very rare in children and primary adrenal teratomas are extremely rare.[1] The retroperitoneal teratomas account for $4 \%$ of all primary teratomas. Antenatally diagnosed suprarenal tumors are rare and their management guidelines have not been fully defined. Antenatal diagnosis of these tumors is increasing because of the extensive use of prenatal ultrasound.[2]

We are reporting here a case of antenatally diagnosed adrenal teratoma in a patient with Down syndrome.

\section{CASE REPORT}

A one-year-old female child presented with antenatally diagnosed right suprarenal cystic mass. The mass was detected on a routine antenatal ultrasound scan at 34 weeks gestation. The perinatal period was uneventful. Baby was born by spontaneous vaginal delivery at term.Patient had features of Down syndrome (Figure 1) which was confirmed on karyotyping. Routine blood investigations were within normal limits including complete blood counts, renal function test, liver function test and serum electrolytes. Thyroid function test, Twentyfour hours urinary vanillylmandelic acid (VMA), homovanillic acid (HVA) levels, and 2D Echo were normal. An ultrasound scan revealed a large complex (solid and 
cystic) mass lesion, about $82 \times 49 \times 58 \mathrm{~mm}$ in size, in right suprarenal region abutting upper pole of right kidney.

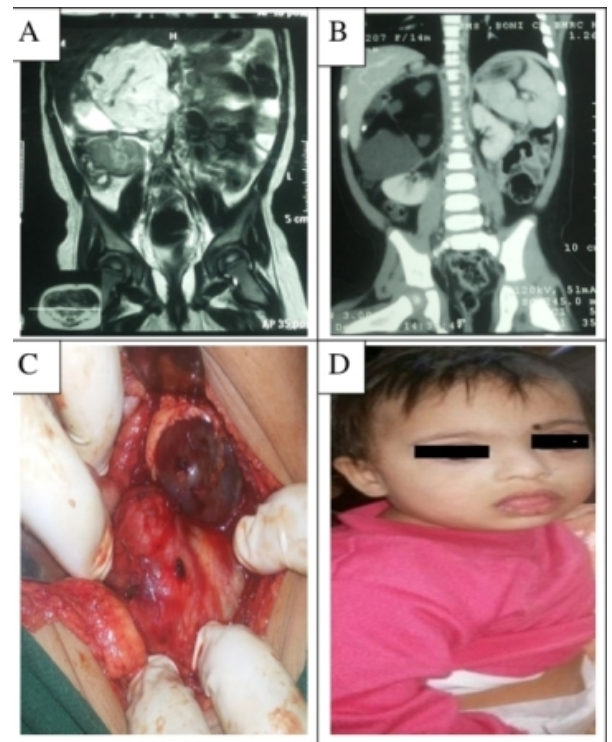

Figure 1: A) CECT image, (B) MRI image, (C) Per-operative photo, (D) Downs facies

Contrast-enhanced computed tomography showed heterogenous mass $(75 \times 54 \times 69 \mathrm{~mm})$ with calcification in right suprarenal region; displacing the kidney inferiorly, pancreas anteriorly and abutting the inferior surface of the right lobe of liver and head and neck of the pancreas, inferior vena cava, aorta, and portal vein (Figure 1). MRI abdomen showed a well-defined encapsulated lesion $(66 \times 60 \times 68)$ in right suprarenal region (Figure 1). On USG guided Tru-cut biopsy, only clear fluid could be aspirated.

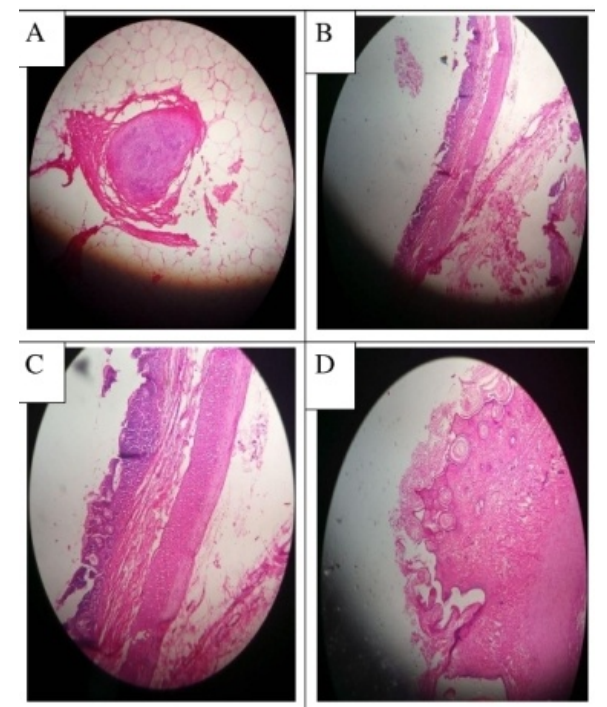

Figure 2: Histopathology slides (A) Cartilage, (B \& C) Intestinal epithelium, (D) Squamous epithelium
Fluid smear showed acellular and pink proteinaceous material. Laparotomy revealed a large tense cystic lesion in the right suprarenal location (Figure 1). Right adrenal gland could not be seen separately from the mass. Tumor was excised completely with no gross residue (Figure 1). Histopathology revealed features of mature cystic teratoma. Microscopically the tumor comprised of mature adipose tissue along with bony and cartilaginous tissue, intestinal epithelium and stratified squamous epithelium with keratinization (Figure 2). Immature elements were not identified. Postoperative period was uneventful and patient was discharged after seven days and remained well in follow up for the last one year without any recurrence

\section{DISCUSSION}

Prenatal detection of fetal anomalies and masses has become increasingly common with the growing use of ultrasonography. Neuroblastoma is the most common suprarenal mass detected during prenatal ultrasonography, but suprarenal masses can also represent an adrenal hemorrhage, extrapulmonary sequestration, a bronchogenic cyst, or renal dysplasia.[3] Precise diagnosis of these antenatally detected lesions is not possible in all patients. Our case was also detected antenatally.

The retroperitoneal teratomas are rare and those involving the adrenal glands are even rarer. On English literature search, less than ten cases have been reported in children and adolescents.[4] These tumors are subdivided into mature, immature, and malignant teratomas. The most common extragonadal site for teratoma is the sacrococcygeal and presacral region. Additionally, teratomas have been reported to occur in the anterior mediastinum, retroperitoneum, tongue and cranial regions.[5, 6]

It is generally accepted that extragonadal germ cell tumors (EGGCTs) follow the same principles of development from primordial germ cells as primary gonadal germ cell tumors. Their migration from the yolk sacendoderm to the genital ridge occurs in the midline. Aberrant migration results in of these primordial germ cells results in tumors at extragonadal sites. There has been no reported case of recurrence in adrenal teratoma. We have been doing follow up 3 monthly with ultrasonography and serum AFP level for the last one year without any recurrence.

Adrenal teratomas are usually benign, and are not associated with elevated tumor markers unless malignan- 
cy is present. The retroperitoneum provides a large space for the mass to grow; thus these tumors are large at the time of presentation. Most of the patients with adrenal teratomas are asymptomatic, but some may present with abdominal or flank pain. Ultrasonography shows a mixed echo in the mass, hyperechoic fat-rich ingredients and hypoechoic cystic areas, with a clear boundary and regular morphology.[7]

CT scan shows mixed density elements, such as fat, bone and other soft tissue densities with septations and calcifications.[8] It has been reported that 93\% of these lesions contain fat components and $56 \%$ contain calcifications.[9] Magnetic resonance imaging often reveals equal signals on T1-weighted imaging (T1WI) and slightly higher signals on T2WI, with a nodular focus and clear boundary.[10]

A postoperative pathologic examination is required for a definitive diagnosis. In our case, Tru-cut biopsy was not useful due to cystic nature and MRI was more informative.

Surgical complete resection and close follow-up should is recommended for mature teratomas.[11] The prognosis is excellent for benign adrenal teratoma if complete resection is accomplished. Retroperitoneal laparoscopic resection of the adrenal tumor is also reported in literature.[12] Down syndrome has a well-known association with neoplasms such as lymphoma, retinoblastoma, and testicular germ cell tumors.[13-15].

Ehara et al in a retrospective study on 1514 cases of Down's syndrome from an autopsy database found 104 cases with malignant neoplasm out of which $83.7 \%$ were haematopoietic malignancies and $16.3 \%$ solid tumors (hepatocellular carcinoma, extrahepatic cholangiocarcinoma, gallbladder adenocarcinoma, brain tumors, and seminoma). [16] Kobayashi et al reported two cases of retroperitoneal teratomas in infants with Down syndrome.[17] Stage et al reported seven infants with Down syndrome having teratomas. Out of these five were retroperitoneal in location.[18].

Consent: Authors declared that they have taken informed written consent, for publication of this report along with clinical photographs/material, from the legal guardian of the patient with an understanding that every effort will be made to conceal the identity of the patient however it cannot be guaranteed.

Authors' Contribution: Both authors contributed equally in concept, literature review, and drafting of the ma- nuscript. Both authors approved the final version of this manuscript.

\section{REFERENCES}

1. James J, Dhillon GS, Blewett CJ, Halldorsson A, Cecalupo AJ. A large adrenal teratoma in a neonate. Am Surg. 2009; 75: 347-9.

2. Alamo L, Beck-Popovic M, Gudinchet F, Meuli R. Congenital tumors: imaging when life just begins. Insights into Imaging. 2011; 2:297-08.

3. Oguzkurt P, Ince E, Temiz A, Demir S, Akabolat F, Hicsonmez $A$, et al. Prenatal diagnosis of a mass in the adrenal region that proved to be a teratoma. J Pediatr Hematol Oncol. 2009; 31:350-51.

4. Garg A, Pollak-Christian E, Unnikrishnan N. A rare adrenal mass in a 3-month-old: A case report and literature review. Case Rep Pediatr. 2017; 4542321:5.

5. Selimoglu E, Ozturk A, Demirci M, Erdogan F. A giant teratoma of the tongue. Int J Pediatr Otorhinolaryngol. 2002; 66:189-92.

6. Ratan SK, Ratan J, Kalra R. Large benign cystic teratoma of the mesosigmoid causing intestinal obstruction: report of a case. Surg Today. 2002; 32: 922-4.

7. Resnick EL, Talmadge JM, Winn SS. Mediastinal teratoma diagnosed via ultrasound-guided biopsy. Ultrasound Q. 2013; 29:245-6.

8. Park SB, Cho KS, Kim JK. CT findings of mature cystic teratoma with malignant transformation: Comparison with mature cystic teratoma. Clin Imaging. 2011; 35:294-300.

9. Yamashita $Y$, Torashima M, Hatanaka $Y$, Harada M, Sakamoto $\mathrm{Y}$, Takahashi M, Miyazaki K, Okamura $\mathrm{H}$. Value of phase-shift gradient-echo MR imaging in the differentiation of pelvic lesions with high signal intensity at T1-weighted imaging. Radiology. 1994; 191:759-64.

10. Manchali MM, Sharabu C, Latha M, Kumar L. A rare case of oropharyngeal teratoma diagnosed antenatally with MRI. J Clin Imaging Sci. 2014; 4:15.

11. Sato F, Mimata H, Mori K. Primary retroperitoneal mature cystic teratoma presenting as an adrenal tumor in an adult. Int J Urol. 2010; 17:817.

12. Li S, Li H, Ji Z, Yan W, Zhang Y. Primary adrenal teratoma: Clinical characteristics and retroperitoneal laparoscopic resection in five adults. Oncology Letters. 2015; 10:2865-70.

13. Satge D, Schorderet DF, Balmer A, Beck-Popovic M, Addor MC, Beckmann JS, Munier FL. Association Down syndrome-retinoblastoma: a new observation. Ophthalmic Genet. 2005; 26:151-52.

14. Hsiung Stripp DC, Vaughn D, Van Arsdalen K, Whittington $R$. Three cases of advanced seminoma and Down's syndrome: a possible association. Am J Clin Oncol. 2003; 26:197-9.

15. Satge D, Le Tourneau A, Verger JP, Lefort S, Geneix A, Malet P, Diebold J, Vekemans M. A case report of Down syndrome and centroblastic lymphoma. Pathol Res Pract. 1996; 192:1266-9. 
16. Ehara $\mathrm{H}$, Ohno $\mathrm{K}$, Ito $\mathrm{H}$. Benign and malignant tumors in Down syndrome: analysis of the 1514 autopsied cases in Japan. Pediatr Int. 2011; 53:72-7.

17. Kobayashi T, Sakemi $\mathrm{Y}$, Yamashita $\mathrm{H}$. Increased incidence of retroperitoneal teratomas and decreased incidence of sacrococcygeal teratomas in infants with Down syndrome. Pediatr Blood Cancer. 2014;61:363-5.

18. Satge $D$, Sommelet $D$, Geneix A, et al. A tumor profile in Down syndrome. Am J Med Genet. 1998; 78:207-16.. 